\title{
Surviving, being resilient and resisting: teachers' experiences in adverse times
}

\author{
Maria Assunção Flores \\ Institute of Education, University of Minho, Braga, Portugal
}

\begin{abstract}
This paper reports on a three-year research project aimed at examining experiences of being a teacher in a context of school reform and adverse times. A mixed-method research design was devised, including a national survey, semi-structured interviews, focus groups and a professional development programme. Findings suggest that teachers face old and new demands in a context of school reform and adverse times along with the worsening of their working conditions, the deterioration of their socio-economic status and the lack of career prospects. Some of them try to survive; others resist feelings of giving up by becoming more resilient and resisting. Professional values, a sense of professionalism and identity, along with the relational and emotional dimensions of teaching, and, in some cases, school culture and leadership, explain the ways in which some teachers became more resilient and resistant than others.
\end{abstract}

\section{ARTICLE HISTORY}

Received 25 January 2019

Accepted 22 August 2019

\section{KEYWORDS}

Teachers' lives; teaching; working conditions; professionalism; resilience

\section{Introduction}

Much has been written about teachers' work and lives over the last decades. Existing literature shows the complexity and interplay of the variables that influence and impact on teachers' work and lives (see, for instance, Ávalos, 2013; Day, 2017; Flores, 2012). In many parts of the world, it is possible to identify issues such as the rise of performative cultures through increased accountability and imposition of standards (Sachs, 2016), the compliance of teachers with the demands of performance policies and the tyranny of audit (Lo, 2012), and the decline in teacher autonomy and an environment of distrust (Sachs \& Mockler, 2012). However, less is known about the ways in which teachers' work and lives are challenged in contexts marked by contradictory trends, particularly in times of austerity and intense school reform. These challenges are related to an imposed curriculum, but at the same time to the exhortation of teacher autonomy as well as to an expansion of teachers' roles, along with a decrease in their socioeconomic status and the deterioration of their working conditions, as in the case of the Portuguese teachers, particularly over the last decade. In general, teachers' work and lives have become more and more characterised by complexity and intensification which are often associated with societal and technological changes, as well as with the bulk of reforms that they need to implement in schools and in classrooms (Ballet, 
Kelchtermans, \& Loughran, 2006; Flores, 2014; Flores, Day, \& Viana, 2007; Sugrue, 2006). This paper reports on findings from a wider three-year research project aimed at examining Portuguese teachers' experiences of being a teacher within a context of school reform and austerity measures.

\section{Teachers' work and lives: key issues in international literature}

Existing literature has identified the intensification of a normative perspective of teaching and the experience of teachers in doing more than one thing at a time and thinking about their work at all times (Brante, 2009). Growing instrumentalism and management in teaching (Klette, 2002), increasing bureaucracy and the existence of a 'huge amount of rules and regulations' according to which teachers are expected to operate with implications for teachers' morale, commitment and effectiveness have also been discussed (Ben-Peretz \& Flores, 2018; Day, 1997; Day \& Smethem, 2009; Flores et al., 2007; Sugrue, 2004).

The existence of greater control over teachers' work and performance of schools (Ball, 2003), of accountability mechanisms leading to more pressure upon schools and teachers to increase standards of teaching, learning and achievement (Day \& Smethem, 2009; Osborn, 2006), and of standardisation and overregulation (Hargreaves, 2003) have affected teachers' daily professional lives. A decrease in teacher motivation, job satisfaction and sense of professionalism (Day, Flores, \& Viana, 2007) has been identified along with perceptions of an erosion of autonomy (Day, 1999) and feelings of powerlessness (Estrela, 2001), teacher stress, fatigue and burnout (Esteve, 1991; Flores, 2014). Looking at the opportunities and threats in teaching, amongst other features, Hargreaves and Fullan (2012, p. 43) note that there was 'more interactive professionalism among teachers', but they also warn that it 'can turn into hyperactive professionalism as teachers are thrown into hurried meetings to devise quick-fix solutions that will lead to instantaneous gains in student achievement results'. This culture of performativity is seen, for instance, in standard-based testing, audit procedures and methods for self-evaluation, school inspection, league tables, scripted curricula, teacher performance management, and so on (Day \& Smethem, 2009; Flores et al., 2007; Kelchtermans, 2009).

Teachers' work has tended to become more fragmented, while opportunities to learn beyond the classroom walls have increased enormously due to the technological revolution (Day, 1999, 2017; Day \& Sachs, 2004; Hargreaves, 2001; Klette, 2002). As such, new expectations and demands were placed upon schools and teachers even if their working conditions, their education and professional development opportunities, and the resources allocated to them, did not correspond with the greater challenges and demands (Flores, 2012). A more restricted view of teacher professionalism related to the 'technicisation' of teaching (in which norms and top-down directives are key features) entails an outcome-led orientation and fragmentation of teachers' work while, at the same time, a more interactive and collaborative professionalism is advocated in which teachers' sense of agency and the moral and social purposes in improving the quality of education provided for pupils are of paramount importance (Hargreaves \& O’ Connor, 2017).

Discussing the impact of international agendas on the Irish education system, Sugrue (2006), for instance, highlights an increase in the performativity and accountability demanded of teachers; he stresses its negative impact in terms of the 'marginalisation of 
other important values, as part of the educative process, with particular reference to the democratisation of schooling, citizenship and the health of society'. In a similar vein, Kelchtermans (2009, p. 66) cautions that performativity entails a 'reductionist conception of education' as it reduces and changes what counts as teaching and quality learning and what it means to be a teacher, 'ignoring or even denying important aspects of the educational reality' which constitute 'powerful sources of motivation, commitment and job satisfaction for teachers'. Also, Ben-Peretz (2012), analysing the effects of the external surveillance mechanisms and the logics of regulation and measurement that have extended teachers' dilemmas as professional educators and interpreters of educational policies, advocates the need to find a balance between accountability and professional autonomy in order to adapt accountability policies to the contexts of teachers.

More recently, research literature has shown the risk factors related to contexts of teaching seen as adverse and challenging, such as heavy workload, classroom management, feelings of unpreparedness, lack of support, lack of resources, and so on (Jenkins, Smith, \& Maxwell, 2009; McCormack \& Gore, 2008; Sumsion, 2004). Pearce and Morrison's (2011) study has investigated the impact of professional, individual and relational conditions on the resilience of early career teachers and has highlighted the importance of understanding how they engage in the formation of professional identities. Resilience has, therefore, become a key theme in examining teachers' work and lives in recent years (Wosnitza, Peixoto, Beltman, \& Mansfield, 2018). As a multidimensional and socially constructed concept (Gu \& Day, 2007), in which context plays a key role (Mansfield, Beltman, Price, \& McConney, 2012), resilience is dependent on support, both formal and informal (Papatraianou \& Le Cornu, 2014), but also on teachers' professional values and beliefs. Understanding resilience as 'a construct that is relative, developmental, dynamic, connoting the positive adaptation and development of individuals in the presence of challenging circumstances' (Gu \& Day, 2007, p. 1305) may offer possibilities to examine teachers' work and lives in contexts that are marked by increasing contradictory demands and expectations along with intense school reform in challenging times.

\section{The context of the study}

Over the last years Portugal has gone through a financial and economic crisis, with implications for all sectors of society, and particularly Education. Austerity measures had been intensified since the implementation of the Memorandum of Understanding with the International Monetary Fund, the European Central Bank and the European Commission, known as the Troika (2011-2014). In addition to the economic and social effects of the crisis, issues such as the lowering of the budget for education, salary cuts and lack of career progression, the increase of poverty among children and families, the growing emphasis on an outcome-led orientation perspective to teaching and policies of accountability, intensification and bureaucratisation of teachers' work emerged (Flores, 2012, 2014; Flores \& Ferreira, 2016). As such, teachers' work and lives have been greatly challenged. Amongst the key aspects that characterise the teaching profession in such adverse contexts are the deterioration of teachers' working conditions, precarious job situations and the impoverishment of the teaching workforce, the lowering of teachers' status and their social image, the high level of unemployment, salary cuts and lack of 
career prospects. Along with these were changes at a policy level which included new mechanisms for teacher evaluation, new protocols for school governance, the introduction of national exams, and so on. In general, more pressure was placed on schools and teachers to increase teaching standards and student achievement. Teacher surplus and the ageing of the teaching workforce are two features that also characterise the teaching profession in the Portuguese context.

\section{The study: purposes, methods and participants}

This paper draws upon a wider three-year research project funded by Fundação para a Ciência e a Tecnologia (National Foundation for Science and Technology) (PTDC/ CPE-CED/112164/2009) aimed at examining, amongst other features, existing conditions of teaching and being a teacher in a context of intense school reform. Policy initiatives associated with a context of austerity and economic crisis in Portugal have affected teachers' work and lives in many ways, including an increase in workload and bureaucracy and the deterioration of their working conditions, as well as of their social and economic status. In this paper the following research questions are addressed:

(1) How do Portuguese teachers look at their experience as teachers in adverse circumstances (e.g. intensive school reform and austerity measures)?

(2) How do they see the contexts in which they work?

(3) What kinds of factors influence their professional lives in adverse times and how do they cope with them?

\subsection{Data collection}

A mixed-method research design was devised (Figure 1) The project included three phases of data collection, which took place between 2012 and 2014. In the first phase, a national survey was conducted in which 2702 teachers participated. A second phase of data collection was then carried out (phase II) through semi-structured interviews with principals in 11 schools located in different regions of the country, as well as with focus groups with 99 teachers and
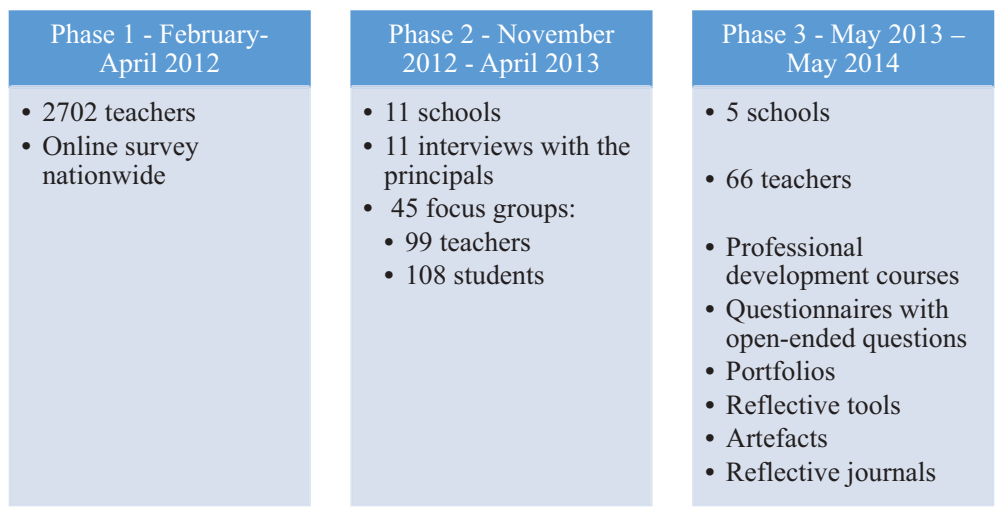

Figure 1. Phases, methods and participants in the research project. 
108 students. Finally, phase III included a professional development programme carried out in five schools located in northern Portugal, in which 66 teachers participated.

This research project carried out in the Portuguese context enabled the analysis of teachers' work and lives through their own voices, and also the taking into account of the views of principals and students using a variety of methods. First, a nationwide survey was conducted through an online questionnaire (using SurveyMonkey) which was sent to the principals of all elementary and secondary schools in mainland Portugal. The questionnaire was then distributed to the teachers in each school. Permission for administering the questionnaire in public schools was previously obtained from the Portuguese Ministry of Education. The questionnaire (which draws on previous research) [Day et al., 2007; Flores et al., 2007]) included both closed and open-ended questions according to two main dimensions: (i) motivation and job satisfaction (including questions about current motivation, areas in which teachers experienced the greatest increase in satisfaction, the most dissatisfaction and so on); and (ii) leadership, autonomy and school culture. In order to analyse further teachers' work and lives associated with the effects of policy initiatives arising from the quantitative data, focus groups were held with 99 teachers in 11 schools throughout the country. Each focus group was made up of three to seven participants. Teachers participating in the focus groups were recruited by the principal in each of the 11 participating schools. The principals were asked to identify key informants in their schools who would be willing to share their views and experiences of teaching and being a teacher in a context of massive school reform. A diversity of criteria was sought, such as years of experience, gender, sector of teaching, roles performed at school, subject taught and so on. The volunteer participating teachers in the focus group came from a variety of backgrounds and their opinion was considered to be illustrative of teachers' experience in their schools. Similar criteria were used to select the pupils to participate in the focus group in each of the schools.

The focus group protocol included questions related to perceptions of school culture and leadership, and changes in teachers' work, as well as issues related to being a teacher and to teaching as a profession. The focus groups were conducted in each of the schools by at least two researchers participating in the wider research project. Student focus groups from the 11 schools were also conducted to learn from their views of teaching and being a teacher, as well as issues of school culture and leadership. The 11 principals were also interviewed. A one-year professional development programme was then conducted (phase III) in five schools in order to gain further insights into teachers' professional work. The 66 participating teachers developed projects based on their daily professional concerns and they were able to present, discuss and evaluate them over one year. Teachers welcomed the programme and they described it as a 'therapy' in their professional lives, as it enabled them to share their concerns, experiences and projects for the future.

\subsection{Participants}

In total, in phase I, 2702 teachers from mainland Portugal responded to the questionnaire (Table 1): $78.5 \%$ were female; $42.8 \%$ of them were between $40-49$ years old; $28.6 \%$ were between 50-59 years old; and 25.5\% were between 30-39 years old. Only $1.7 \%$ were between 20-29 years of age. In relation to their qualifications, the majority of the 
Table 1. Teachers participating in the survey.

\begin{tabular}{|c|c|c|}
\hline Demographic characteristics & $n$ & $\%$ \\
\hline \multicolumn{3}{|l|}{ Gender } \\
\hline Male & 371 & 21.5 \\
\hline Female & 1355 & 78.5 \\
\hline Missing & 976 & \\
\hline \multicolumn{3}{|l|}{ Age } \\
\hline [20-29] & 29 & 1.7 \\
\hline [30-39] & 441 & 25.5 \\
\hline [40-49] & 740 & 42.8 \\
\hline [50-59] & 495 & 28.6 \\
\hline [Over 60] & 24 & 1.4 \\
\hline Missing & 973 & \\
\hline \multicolumn{3}{|l|}{ Academic degree } \\
\hline Bachelor & 36 & 2.1 \\
\hline Licenciatura & 1027 & 59.3 \\
\hline Postgraduate Course & 270 & 15.6 \\
\hline Master's Degree & 370 & 21.4 \\
\hline $\mathrm{PhD}$ & 30 & 1.7 \\
\hline Missing & 969 & \\
\hline \multicolumn{3}{|l|}{ Years of experience } \\
\hline$[0-10]$ & 264 & 15.4 \\
\hline [11-20] & 639 & 37.6 \\
\hline$[21-30]$ & 594 & 34.9 \\
\hline [31-40] & 204 & 12 \\
\hline [Over 41] & 1 & 0.1 \\
\hline Missing & 1000 & \\
\hline \multicolumn{3}{|c|}{ Years of experience in the current school } \\
\hline$[0-10]$ & 1110 & 65.8 \\
\hline [11-20] & 419 & 24.8 \\
\hline$[21-30]$ & 147 & 8.7 \\
\hline [31-40] & 12 & 0.7 \\
\hline Missing & 1014 & \\
\hline \multicolumn{3}{|l|}{ Positions in the school } \\
\hline Permanent post at school & 1412 & 83.3 \\
\hline Contract teachers & 283 & 16.7 \\
\hline Missing & 1007 & \\
\hline \multicolumn{3}{|l|}{ Type of school } \\
\hline Urban & 885 & 51.1 \\
\hline Suburban & 469 & 27.1 \\
\hline Rural & 377 & 21.8 \\
\hline Missing & 971 & \\
\hline Total & 2702 & 100 \\
\hline
\end{tabular}

teachers held a Licenciatura degree (59. 3\%) and 21. Four per cent held a master's degree $(21.4 \%)$. The majority of the participants had between 11 and 20 years of experience $(37.6 \%)$ and between 21 and 30 years (34.9\%). Most of the participants had between 1-10 years of experience in their present school $(65.8 \%)$. The majority of the participants had a permanent post at school $(83.3 \%)$. In addition, the majority of them taught in urban schools $(51.1 \%)$ and in all sectors of teaching (from pre-school to secondary school: 3 to 18 -year-old pupils). Most teachers taught in 3rd cycle $(41.9 \%)$ (pupils aged 12-15) and in secondary education (33.2\%) (pupils aged 16-18).

The majority of the teachers participating in the focus groups were female teachers (76.8\%) with $31.3 \%$ aged between 51 and 60 years old and $27.3 \%$ between 41 and 50 years old (Table 2). The participating teachers came from all sectors of teaching, from pre-school to secondary school, and taught various subjects. In regard to their experience as teachers, $36.4 \%$ had between 21 and 30 years of service, $26.3 \%$ between 31 and 40 , and $22.2 \%$ between 11 and 20 years of experience. 
Table 2. Teachers participating in the focus group.

\begin{tabular}{|c|c|c|}
\hline Demographic characteristics & $n$ & $\%$ \\
\hline \multicolumn{3}{|l|}{ Gender } \\
\hline Male & 23 & 23.2 \\
\hline Female & 76 & 76.8 \\
\hline \multicolumn{3}{|l|}{ Age } \\
\hline [31-40] & 8 & 8.1 \\
\hline$[41-50]$ & 27 & 27.3 \\
\hline$[51-60]$ & 31 & 31.3 \\
\hline [Over 61] & 1 & 1.0 \\
\hline No Information & 32 & 32.3 \\
\hline \multicolumn{3}{|l|}{ Sectors of teaching ${ }^{a}$} \\
\hline Preschool & 11 & 11.1 \\
\hline 1st Cycle & 18 & 18.2 \\
\hline 2nd Cycle & 20 & 20.2 \\
\hline 3rd Cycle & 13 & 13.2 \\
\hline 2nd and 3rd Cycles & 3 & 3 \\
\hline Secondary school & 32 & 32.3 \\
\hline Special Needs Education & 2 & 2 \\
\hline \multicolumn{3}{|l|}{ Teaching areas } \\
\hline Exact Sciences & 21 & 21.2 \\
\hline 1st Cycle (Primary) & 18 & 18.2 \\
\hline Languages & 17 & 17.2 \\
\hline Social Sciences and Humanities & 13 & 13.2 \\
\hline Preschool & 11 & 11.1 \\
\hline Arts & 7 & 7.1 \\
\hline Vocational training & 4 & 4.0 \\
\hline ICT & 3 & 3.0 \\
\hline Special Needs Education & 2 & 2.0 \\
\hline Other & 1 & 1.0 \\
\hline No information & 2 & 2.0 \\
\hline \multicolumn{3}{|l|}{ Years of experience } \\
\hline$[6-10]$ & 1 & 1.0 \\
\hline$[11-20]$ & 22 & 22.2 \\
\hline$[21-30]$ & 36 & 36.4 \\
\hline [31-40] & 26 & 26.3 \\
\hline No Information & 14 & 14.1 \\
\hline \multicolumn{3}{|l|}{ Years of experience in the current school } \\
\hline$[6-10]$ & 38 & 38.5 \\
\hline$[11-20]$ & 22 & 22.2 \\
\hline$[21-30]$ & 12 & 12.1 \\
\hline [31-40] & 3 & 3.0 \\
\hline No Information & 24 & 24.2 \\
\hline Total & 99 & 100 \\
\hline
\end{tabular}

In general, the age of the teachers participating in the survey and in the focus groups is in line with the official statistics described in the 'General profile of the teachers' in Portugal, published by the Ministry of Education. According to the last official statistics, $48.4 \%$ of the teachers in Portugal are 50 years or older and only $0.4 \%$ are 30 years of age or younger, figures that apply to the public sector (Direção-Geral de Estatísticas da Educação e Ciência [DGEEC], 2018).

In regard to the 108 students participating in the focus groups (23 in total) most were female (52.8\%) (Table 3). Most of them were aged between 11 and 15 (39.8\%) and between 16 and $20(30.6 \%)$. The participants came from all sectors of teaching, from Kindergarten, primary school, elementary school and secondary school. Of the 108 pupils, $32.4 \%$ were in secondary school and $25.9 \%$ in elementary school (students aged 10 to 15 ). 
Table 3. Pupils participating in the focus group.

\begin{tabular}{lrr}
\hline Demographic characteristics & $n$ & $\%$ \\
\hline Gender & & \\
Male & 51 & 47.2 \\
Female & 57 & 52.8 \\
Age & & \\
{$[\geq 5]$} & 9 & 8.4 \\
{$[6-10]$} & 23 & 21.4 \\
{$[11-15]$} & 43 & 39.8 \\
{$[16-20]$} & 33 & 30.6 \\
Sectors of teaching & & \\
Preschool & 10 & 9.3 \\
1st Cycle (Primary) & 16 & 14.8 \\
2nd Cycle & 19 & 17.6 \\
3rd Cycle & 28 & 25.9 \\
Secondary & 35 & 32.4 \\
Total & $\mathbf{1 0 8}$ & $\mathbf{1 0 0}$ \\
\hline
\end{tabular}

Of the 11 principals, six were female and they came from all sectors of education, including big clusters of schools (from pre-school to secondary schools) (7); four worked in the secondary school sector only.

\subsection{Data analysis}

Quantitative data were analysed statistically with the use of SPSS (version 20). The process of qualitative data analysis was undertaken according to two phases: an analysis of data gathered in each school through the voices of teachers, pupils and the principal. A second phase was then carried out according to a comparative or horizontal analysis (cross-case analysis) (Miles \& Huberman, 1994). In this phase, it was possible to look for common patterns as well as differences. Qualitative data were analysed according to a thematic analysis. Key themes and sub-themes arising from the interviews and focus group were identified, looking for the views of each of the stakeholders. In order to avoid subjectivity the data were analysed by at least two researchers. The most frequent trends were then summarised and labelled accordingly. Then, lists of categories were compared and adjusted to reach consensus by four researchers. The categories were obtained through an iterative process which included separate coding, comparing results and reaching agreement. Joint discussions and analyses of emerging themes and subthemes were held with the research team in order to ensure relevance, triangulation and trustworthiness of the findings. The key themes were then grouped in several general categories, for instance, factors which affect teachers' work and lives; strategies used by teachers to deal with current challenges; impact of policy initiatives on teachers' work; factors leading to an increase or decrease in job satisfaction over time, and so on (Flores, 2014). In this paper, three main themes are examined, as will be described in the next section. Abundant quotes from the participants will be included to illustrate teachers' voices. The aim is to gain insights into the challenges that Portuguese teachers faced in times of intense school reform and adverse circumstances as well as the ways in which they dealt with them through their lived first-person experiences. 


\section{Findings}

The findings from the research are presented below according to three main themes integrating both quantitative and qualitative data: (i) changes in the teaching context: old and new demands; (ii) surviving and being resilient; and (iii) resisting and maintaining hope in teaching: sources of motivation and commitment. Quotations used to illustrate the main themes are drawn from the focus groups with teachers and pupils and from the interviews with the principals.

\subsection{Changes in the teaching context: old and new demands}

Teachers' accounts are evocative of the changes in teaching and of the ways in which their lives have been affected. Issues such as an increase in workload, an increase in administrative tasks, professional instability and insecurity, precarious jobs, intensification and bureaucratisation are recurrent elements in their accounts:

Bureaucracy is all over your work ... you need to report on everything, bureaucratic tasks have increased over the last few years [...] Every year there is something new. Your work is more and more demanding in terms of bureaucratic tasks. (Secondary school teacher, 23 years of teaching)

There are lots of documents that you need to fill in. I mean you could do important work at the department meetings. But because of changes you always need to adapt documents. So every year there is always something new to be done. Changes in government mean ongoing changes. [...] But pressure is too high, you need to do meetings, you need to adapt things that sometimes in practice are meaningless. (Primary school teacher, 26 years of teaching)

When asked about the changes that took place in teaching, teachers participating in the national survey claim that their working conditions deteriorated over the last few years. They state that their workload has increased (96.7\%), bureaucracy has increased (95.4\%), there was an accentuation of criticism of teachers (92.2\%), there was greater control over teachers' work (75.6\%), and there was an increase in teachers' public accountability (74.6\%). They also reported that the negative image of teaching and teachers in the media $(90.0 \%)$ has led to the deterioration of the teaching profession. The principals also corroborate this view:

What you see is the proletarisation of teachers' work [....] There are things that were in place before but others are a result of the situation of the country and of the intervention of Troika, including salary cuts and all of the negative image about teaching and teachers in the media. (Principal A)

There is heavy workload ... . Nowadays you need to do more in schools with fewer resources. This means extra work for you as a teacher ... and you need to do your best against the odds. (Elementary school teacher, 27 years of experience)

The most problematic factor is the news, the lack of safety and instability in economic terms, the reduction of the salary [...] you never know what tomorrow will bring. (Secondary school teacher, 21 years of experience) 
The pupils also contribute with interesting insights into being a teacher in challenging times. Issues such as intensification, paperwork, tiredness and worsening of teachers' working conditions were recurrent elements in their focus groups:

The school influences teachers' lives. They spend lots of time at school in order to prepare their teaching and the written tests, I mean, this must be really tiring. (P42)

My mother is a teacher and I can tell how much she works! Almost every day she gets home tired and with lots of work to be done ... and she says to me: 'Please, don't be a teacher!' (P16).

For instance, now with Troika, and the financial crisis, there was a reduction in teachers' salary. And I guess they are upset about that ... (P2).

Teachers have to do lots of marking and they need to check homework and everything. They need to work a lot. And they need to work at home too. I also think that it is hard for them to get us motivated and have confidence in teaching. I think teachers' work is strict. (P56).

A similar view is held by the principals. They stressed the deterioration of teachers' working conditions, the decrease in their socio-economic status, and the negative image of teaching and teachers disseminated in the media:

Teachers' motivation has decreased due to the economic situation we are going through and also due to the salary cuts, high taxes and other issues related to the deterioration of teachers' social image. (Principal F)

A social image has been created that is not good for teachers; it is a narrative in which teachers have lots of privileges, including long holidays, great salaries that do not correspond to what they actually do. (Principal H)

Some teachers highlighted the ways in which their lives have been affected by the deterioration in their working conditions. The lack of career prospects, the lack of valorisation of the teaching profession, the lack of motivation and feelings of tiredness and disappointment are recurring elements in their accounts. Some of the participants spoke of teachers who have decided to leave the teaching profession ahead of time:

The lack of motivation is leading many people to leave teaching. They have asked to be retired ahead of time. As a teacher you are confronted with a novelty almost every day and this is hard especially for the oldest teachers. (Secondary school teacher, 23 years of teaching)

Teachers are tired, they are tired of being seen in a negative way, of being mistrusted. There have been too many reforms, too much legislation and so on. There are people that are exhausted and they say 'I am going to retire. I can't stand it anymore'. (Principal E)

The participating teachers also spoke of the effects of changes in the policy environment with massive legislation impacting upon schools and teachers' work, namely new mechanisms for teacher evaluation; new protocols for school governance; reduction in the school curriculum; and the introduction of national exams from primary school upward. The majority of the teachers responding to the survey reported that their motivation and job satisfaction decreased (61.6\% and $44.5 \%$, respectively) over the last years (2009-2012) during which major reforms in Education had been put into place in 
schools. Amongst the policy initiatives that have affected teachers' work are teacher evaluation, a new system for school governance (the merging of schools in large clusters of schools), an increase in the number of pupils per class and of classes per teacher, the increase in workload and so on. Issues such as salary cuts, the deterioration in the social image of teaching, lack of motivation on the part of students, lack of valorisation of school on the part of parents, lack of career prospects and low morale were at the forefront of their accounts.

I feel really tired and my motivation is low. I have 27 years of teaching and with all this intensification of your work it is hard to stay motivated for 18 years more. (Elementary school teacher, 27 years of teaching)

I feel exhausted. My students say: 'Mrs, why do you care so much?' But I do care and I feel awful because I think about my responsibility as a teacher. (Secondary school teacher, 28 years of teaching)

As this last quotation illustrates, many teachers felt lost at sea. On the one hand, they felt tired and demotivated due mainly to external factors such as policy initiatives and a lack of valorisation of the teaching profession; on the other hand, they revealed the inner tensions they need to cope with in their daily lives as teachers, which are related to the core issues of being a teacher, and to their professional values, attitudes and beliefs.

\subsection{Surviving and being resilient}

Some of the teachers, despite all the changes and challenges that they have to deal with in their schools, try to survive and overcome feelings of giving up. They try to become more resilient in order to keep their motivation and joy of teaching in spite of 'all the things that go wrong in education' related to the worsening of working conditions, lack of career prospects, ongoing changes at a policy level associated with greater accountability and performativity within the context of a bureaucratic culture. Even with the challenges, they draw on their sense of vocation (their commitment and willingness to make a difference in their students' lives) in order to face adverse contexts of teaching.

As a teacher you feel demotivated with all that is going on in Education, but you need a positive attitude in order to motivate your students for learning. (Secondary school teacher, 21 years of experience)

I try to make an effort to carry on keeping in mind the goal that has made me choose this profession, I mean, my students! (Elementary school teacher, 22 years of experience)

Even though you are demotivated you need to focus on your pupils' motivation. You want them to do well at school. You are concerned with their learning and well-being. I try to be professional as much as I can ... (Primary school teacher, 26 years of teaching)

Issues such as teachers' sense of professionalism and their capacity for resilience emerged from the data. They spoke of their focus on pupils and on the reasons that led them to teaching in the first place. Issues of self-image as a teacher, professional values and a sense of professionalism, alongside the influence of school culture and leadership, were of paramount importance to explain differences among the participants. 
As a teacher you may be demotivated with regard to salary cuts, and to the lack of career progression, but in regard to your work with your pupils, your classes, the families, etc. you do the best you can. (Elementary school teacher, 17 years of teaching)

The impression that I have in regard to my colleagues is that they are tired, exhausted, demotivated but willing to be with their pupils. You can influence your pupils and this has to do with your action as a professional, your ability to mobilise knowledge and to enhance their motivation [...] Each day you take all your energy and you go to the classroom to get your work done. (Primary school teacher, 25 years of teaching)

There is a true school climate and we need to participate a lot in school activities. I feel good in doing that, I like to teach and I am still learning in this school. I think this is a key factor for your sense of job satisfaction. (Elementary school teacher, 25 years of teaching)

There is great freedom for you to do what you are willing to do at school. If I want to develop a project, I feel supported .... (Elementary school teacher, 15 years of teaching)

Principals' views corroborate teachers' accounts. They stressed the importance of and the need to resist feelings of giving up and being resilient, as well as the need to enhance the political and social dimension of teaching which, according to them, is essential in times marked by turbulence and pressure:

You have to be resilient. I've never felt so disappointed with the system as I do now. I think it is about the lack of job satisfaction but also of a great political and social consciousness that I haven't had before. But I do think that I've never felt so conscious about my role as a leader as I do now. (Principal F)

Trust. I think teachers feel that we trust them. In my school people can take initiative. People feel that they can take risks and if things go wrong we are available to accept that failure. People feel that if something goes wrong they have someone they can turn to. (Principal D)

The participating teachers also spoke of issues such as commitment to students' learning and willingness to grow professionally, despite the negative and less encouraging external working environment; they also stress the positive 'ethos' of their workplace. Some of them stressed that they have clear ideas about what it means for them to be a teacher, which relate to their beliefs, professional values and their capacity for being resilient in adverse contexts of teaching:

I have always said that teaching has been always my profession. I like what I do and I think I am a good teacher. (Primary school teacher, 26 years of teaching)

My motivation comes from the fact that I really enjoy what I do. I really enjoy being a teacher. If I haven't had this motivation I wouldn't be able to get up early in the morning and coming to school sometimes with great sacrifice. [...] I love my kids and I do enjoy working with them. (Primary school teacher, 20 years of teaching)

\subsection{Resisting and maintaining hope in teaching: sources of motivation and commitment}

The participants were asked about what has kept them in teaching. Even if most of them spoke of the lack of social recognition of their work, their low morale and feelings of tiredness and fatigue, issues such as the joy of teaching and commitment to pupils, to 
their learning and well-being were of paramount importance in their daily lives. They stressed the conditions for teaching and learning as well as the development of pupils as citizens. Inclusion, meaningful learning, the affective-relational element in the teaching and learning process, and the promotion of pupil involvement at school were recurring themes in their accounts. This is in line with earlier research in the context of changes in educational policies marked by bureaucratisation in Portugal which showed that negative emotions were related to policy reform, whereas positive ones were related to classroom interactions (Bahia, Freire, Amaral, \& Estrela, 2013).

There is no single teacher who does not have a concern in regard to an ethical and social attitude ... at the end of the day it is about pupils ... the concern of not segregating anyone, of including everyone ... (Pre-school teacher, 28 years of experience)

My motivation may be low at the moment but my dedication is the same. I have hope in teaching, you know ... (Elementary school teacher, 16 years of teaching)

What makes you feel good in your profession is the capability to deal with the kids even in such adverse conditions such as the crisis we are handling now ... (Primary school teacher, 25 years of teaching)

The participating teachers stressed that they stay in teaching because of the pupils, the positive relationships at school, and a supportive and encouraging school culture and leadership. Students were their sources of motivation and the classroom was a safe and enjoyable context; these ideas stand in sharp contrast to an external environment marked by a lack of recognition of the teaching profession, as well as a lack of trust and criticisms in regard to teachers and their work. In other words, some teachers were able to develop feelings of resistance in face of adverse working conditions and focus on their inner sense of identity, their beliefs and professional values.

And now you can ask where I am going to look for strength, willingness and energy to change? I believe this is an inner thing ... the desire to make a difference ... (Pre-school teacher, 28 years of experience)

I really enjoy being with the kids. Coming to school is not a pleasure to me anymore, but I still enjoy being with my pupils. (Pre-school teacher, 33 years of experience)

It is professionalism that makes you do what you do ... nobody is able to deal with so much work ... it is because teachers are professionals that they do what they do. (Elementary school teacher, 33 years of teaching)

Issues of professionalism and sense of vocation are recurring elements in their accounts. The positive and supportive 'ethos' of the workplace was a key factor in teachers' resistance and hope. They spoke of the supportive and encouraging leadership, trust and positive relationships with colleagues and the core element of their profession, i.e. the relationships in teaching and collegial professionalism:

Maybe you learn more when you have a chat with a colleague in the staffroom having a cup of tea or coffee rather than in those compulsory in-service activities that you have to do in order to get credits ... your day-to-day experience is important ... trying to figure out what and why you are doing so and so. This is very important for your professional growth as a teacher as well as sharing materials with colleagues and working closely with them. (Secondary school teacher, 33 years of teaching) 
Although, in general, there was a negative policy environment along with a deterioration in working conditions, some teachers seemed to remain committed to their pupils and to the social and moral purposes of teaching. They held strong values and beliefs about what it means for them to be a teacher, which relate to their professionalism and sense of identity as well as to their capacity for resisting in adverse contexts.

I can say that it is a pleasure to come to school and work with my pupils. You may find this a bit awkward due to the status of the teaching profession nowadays. But I do feel this way. It is really a pleasure for me to work with my pupils in the classroom. (Elementary school teacher, 20 years of teaching)

The principals also stressed the distinction between the external negative factors that affect teachers' work and lives (e.g. massive legislation, negative image of teaching and of teachers, the lowering of their socio-economic status) and the internal factors that keep them in teaching (e.g. commitment to their students, dedication and professionalism and a supportive school culture and leadership):

People are afraid of what is going on in Education, but in terms of dedication and willingness to work with the pupils there has been no change at all. (Principal B)

Teachers are committed; people here are able to separate clearly between the external issues and the professional reality. The main characteristic of teachers in this school is that they enjoy their job in the sense that they assume its values and the school culture. They love what they do. (Principal D)

\section{Conclusion and discussion}

This study illustrates the inner tensions and challenges of being a teacher in adverse contexts of teaching. It highlights the precarious conditions of many Portuguese teachers, but also shows their capacity for being resilient and resisting alongside their willingness to continue to be teachers in face of challenging circumstances. Other teachers struggled to survive in such adverse teaching contexts. In this section, the ways in which teachers live and respond to the increasingly demanding nature of their work are discussed in the light of the changing nature of teacher professionalism which will be explored by drawing on existing international literature. Day (2017, p. 6) identifies five consequences of policy reform for teachers' work: (i) an increase in the workload and bureaucracy related to more detailed and standardising recording and reporting procedures; (ii) the management of teachers' professional learning and development; (iii) the diminution of the traditional isolation of teachers; (iv) increased pressures on teachers to widen their classroom teaching and learning approaches; and (v) teachers' negative responses to change.

In general, the study reported in this paper highlights not only the key themes that mark teachers' lives in times of austerity (e.g. intensification and bureaucratisation of teachers' work; precarious job situations and the impoverishment of the teaching workforce; the lowering of teachers' status and their social image), but it also stresses the complex and inner tensions between disappointment and resignation on the one hand, and energy, resilience and resistance on the other. 


\subsection{Teachers' work in challenging times: survival, resilience and resistance}

Teachers' responses to the changing nature of their work within a context of intensive school reform and economic downturn were dependent upon a number of key factors. Some teachers were clearly situated in a survival perspective which was marked by external pressures linked to greater control, an increase in workload and bureaucracy, greater public accountability, and greater emphasis on an outcome-oriented perspective of teaching along with endless changes in education through top-down policy initiatives, among which is teacher performance assessment. A number of tensions emerged in this scenario, namely between the need to focus on teaching, on teacher collaboration and on pupils' learning needs and well-being, on the one hand, and the pressure for immediate results within a context marked by greater accountability and control on the other. As Lipman (2009, p. 71) argues, accountability regimes 'created and exacerbated contradictions between substantive long-term projects to improve teaching and learning, and short-term accountability-driven goals'. Thus, issues associated with the lack of motivation, low morale, feelings of tiredness and disappointment were reiterated in teachers' accounts, as well as the worsening of working conditions and a lack of career prospects.

Nevertheless, other teachers seemed to find strategies to cope with external pressures. Teachers' strong professional values, their sense of professionalism and their capacity for being resilient and resisting (despite the negative policy environment and the challenging social and economic context) as well as their sense of identity as teachers emerged from the data in explaining the ways in which some teachers became more resilient and resistant than others. Not only does it relate to issues of teacher commitment, self-efficacy, effectiveness and agency, as earlier research has shown (Gu \& Day, 2007; Day \& Gu, 2009; Flores, 2018), but it is also dependent upon teachers' professional values, their sense of individual and collegial professionalism and their identity as teachers, as well as upon contextual factors. As Gu and Day (2007, p. 1314) assert, resilience is determined by 'the interaction between the internal assets of the individual and the external environments in which the individual lives and grows (or does not grow)' (original emphasis).

The nature and dynamic of teachers' interactions, their beliefs, dispositions and professional values are key to understanding better the ways in which they respond to the challenging and sometimes contradictory nature of their work. Their professional attitudes and motivational responses were linked to the moral, social and relational dimensions of teaching. Teachers' professional attitude and their ethical and emotional commitment were highlighted in their accounts as sources of motivation and hope in teaching despite the external negative factors impacting on their lives. They were able to make decisions and choices between what was seen as essential and non-essential in teaching and they highlighted the ethics of care and the moral and social purposes of teaching. Their commitment to pupils, to their learning and well-being was reiterated in their accounts. This view resonates with Cribb's discussion (2009, p. 40) of the 'ethical reasons for resisting work-role pressures'. He continues: 'We might simultaneously accept an obligation to conform while using our individual and collective efforts to redefine and redraw these same role commitments' (p. 40).

In this study, teachers' resistance was also associated, to a great extent, with supportive school leadership and professional relationships with colleagues. Issues of trust and collegial culture were emphasised. The participants highlighted the interplay of internal 
factors such as teacher collaboration, classroom work and the relationship with pupils as key factors and sources of personal and professional motivation. They claim that their motivation for remaining in teaching is related to their strong professional values as teachers, to their sense of vocation and to their professionalism and identity as teachers. This is in line with earlier research which has shown devotion to students, pursuit of personal and professional fulfilment and support from administration, colleagues and the organisation of the school as key elements in understating teacher resilience (Brunetti, 2006). Similarly, research has demonstrated that improving student engagement, experiencing professional challenges and enjoying collegial support were the most important factors influencing teacher decisions to stay in the profession (Burke et al., 2013). This study corroborates these findings, but it also shows the importance of looking at the experience of teachers' resilience and resistance in context, taking into account their core professional values and the contradictions of teaching, particularly in times of intensive school reform. In other words, attention needs to be paid to external definitions of teacher professionalism as well as to the scenarios in which it is exercised in the eyes of the teachers.

\subsection{Understanding the changing nature of teacher professionalism: tensions and core issues}

Findings from this study highlight the tensions and contradictions characterising teacher professionalism. As a contested site (Sachs, 2016), teacher professionalism needs to be understood as a dynamic and context-dependent concept in order to fully understand its complex and interdependent variables. As Estrela (2014) asserts, it is possible to identify old and new professionalisms which represent drawbacks and progress at the same time. As such, teacher professionalism implies going beyond its normative view to include teachers' views and experiences of professionalism in context. What is apparent in the findings from the study reported in this paper is the tension between managerial and top-down understandings of teacher professionalism and the individual, collegial and contextualised responses to the changing nature of teaching. Borrowing the concepts of organisational and occupational professionalism as ideal-types identified by Evetts (2009), it is possible to see how the logic of control, greater public accountability, and the use of standardised procedures within hierarchical structures of decision making is played out in the school contexts, namely in regard to the use of discretionary judgement and autonomy. These two discourses parallel the notions of democratic professionalism focusing on collegial relations and collaborative work practices, as well as of managerial professionalism with a focus on performance and accountability identified by Sachs (2016). As such, tensions exist in teachers' experience of professionalism and the perceptions of the profession from the outside (namely the media and the policy makers). These tensions were visible in the ways in which teachers in this study dealt with what they considered to be the core issues of teacher professionalism: capacity to make decisions, support from colleagues, strong professional values and beliefs, a sense of purpose for teaching and being a teacher, and a commitment to pupils' learning and well-being. Along with these they also identified external factors which were conducive to feelings of disappointment and lack of motivation, particularly resulting from prescriptive top-down policy initiatives marked by performativity and greater control alongside the negative depiction of the teaching profession in the 
media. These findings are in line with earlier research, for instance, in Chile (Ávalos, 2013) and in other contexts (cf. Day, 2017). As Gewirtz, Mahony, Hextall and Cribb (2009, p. 5) argue, teachers need to respond to social changes including 'greater public scepticism towards professional authority combined with a culture of consumerism, demands for public services that are more responsive to diverse cultural and social identities, and transformations in information and communication technologies'.

In a similar vein, Sachs (2016) identifies the factors that shape teacher professionalism, namely performance management and performance cultures, increased accountability and the continued imposition of teacher standards. Policy changes impact on teachers' subjectivities and understandings of professionalism (Gewirtz et al., 2009), as findings from this study have also shown. Similarly, Sachs and Mockler (2012) stress that the 'cultures of performativity' might be seen both as a threat and as an opportunity. They highlight a 'perspective of development' that conciliates the interests of various stakeholders, community, teachers, parents and students, and which balances externally imposed accountability with the development needs of teachers.

This study illustrates the different ways in which teachers responded to massive topdown policy initiatives within the context of a centralised and bureaucratic system and of a profession in particularly difficult circumstances, namely the lowering of economic and social status and the lack of career prospects. Despite this, some teachers became more resilient and resistant than others negotiating and, to some extent, forging ways to exercise their individual and collegial professionalism in more proactive ways. This is in line with earlier research which has shown that teachers might be situated within constrained professionalism as their autonomy in classroom contexts might be influenced by standardisation of curriculum and national exams (Willis \& Haymore Sandholtz, 2009). However, while teacher decisions might be circumscribed by contextual pressures and time demands that influence their professional judgement and expertise, teachers might make use of their professional space even in contexts marked by growing standardisation (OolbekkinkMarchand, Hadar, Smith, Helleve, \& Ulvik, 2017). This view resonates with Cribb's (2009) discussion about 'doing my job' and 'doing the right thing', which are linked to the dilemmas and increasing demands and complexities of teachers' work. Again, the ways in which teachers in this study dealt with the changing and increasingly contradictory nature of their work illustrate well the tensions in managing the bulk of policy initiatives and at the same keeping a sense of purpose for teaching and being a teacher.

Drawing on the Scottish context, Reeves (2009, p. 114) discusses three competing discourses of teacher professionalism 'embedded in multilevelled and mixed practices in schools': bureau professionalism (teachers as experts in their classrooms working in bureaucratic structures); educational operationalism (teachers are closely supervised and are seen as compliant operatives); and 'new' professionalism (associated with collaboration and knowledge sharing). The tensions arising from the co-existence of these three forms of professionalism create, in Reeves' perspective, opportunities for teachers to reinvent and revitalise new forms of professionalism through 'action, argument and alliances within the field of practice' (p. 115). Competing forms of understanding and experiencing teacher professionalism may also be used to discuss the findings arising from the data collected in the Portuguese context. In particular, whilst it was possible to identify more bureaucratic and compliant forms of professionalism, it was also possible to find more proactive, committed and resistant ways through which teachers were able not only to read and navigate the complexity and 
contradictory nature of their work, but also to make choices between what they considered to be the best pedagogical choices, drawing upon the distinction between what is essential and non-essential in the teaching profession. In other words, their actions and decisions may be situated in a continuum between a logic of execution and compliance according to a top-down and linear orientation of teaching and a perspective of resistance, agency and reinvention of their work within a context of profound, endless and contradictory changes in education.

Overall, the study reported in this paper took place in especially challenging circumstances. It provides evidence of the tensions and contradictions which mark teachers' lives, but it also points to examples of committed professionalism, dedication, and care for the students' learning and well-being. Lo (2012, p. 16) argues that: 'Since teachers' actions rely as much on emotions as on intelligence and will, the means of encouraging accountable actions should be motivation rather than coercion.' It is, therefore, important to examine further the nature and form of teacher professionalism in context and the conditions for its development. As Estrela (2014, p. 8) argues:

Research about teacher professionality and professionalism is still in its infancy. We still know little about how teachers define their professionality and professionalism, how they live in their day-to-day situations, how their professional identity is shaped by that definition, what kinds of threats they feel that might challenge it, what kinds of ethical conflicts they live related to the different roles they perform at school, what is the role of reasoning and emotion in their perception and resolution ...

As such, a plural understanding of teacher professionalism is needed in order to acknowledge and investigate the contexts and factors that might hinder or promote its development. One of the key implications of these findings relates to a more serious discussion about the relevant opportunities for teacher professional development. These need to create spaces for teachers to reflect not only on their professional needs, but also on their experience of professionalism in context, including the analysis of the increasingly demanding and contradictory nature of their work and their sense of agency. In particular, opportunities for teacher professional development would entail the need to consider what teaching and being a teacher represent in the context of the digital revolution, in terms of power and control over what is taught (and how) in schools: in other words, the ethical, social, cultural and political dimensions of teaching. Thus, relevant teacher professional development opportunities would encompass both formal and informal dimensions (Avalos, 2011), as well as both functional and attitudinal orientations (Evans, 2008), including those related to what teachers do and how they think, work and feel. This broader view of teacher professional development would focus not only on the nature and scope of teachers' work within the context of teaching as a collective endeavour, but also on issues such as self-efficacy, commitment, moral and social purposes, professional values and identities. Research suggests that more empirical work is needed on collaborative professional development focusing on the ways in which the associations between the functional academic and the attitudinal motivation, commitment and efficacy needs of teachers may be met (Zeng \& Day, 2019). Also, more needs to be done in order to analyse this plural understanding of teachers' lives, one which combines positive and negative elements, but also different sources of motivation, resilience, resistance and hope, especially in adverse contexts. 


\section{Highlights}

- Teachers face a number of demands and challenges in a context of school reform and adverse times;

- Some teachers try to survive; others resist feelings of giving up by becoming more resilient and resisting;

- Strong professional values, a sense of professionalism and identity, and in some cases, school culture and leadership, explain the ways in which some teachers became more resilient and resistant than others.

\section{Acknowledgments}

The author would like to thank Fundação para a Ciência e a Tecnologia (National Foundation for Science and Technology) (PTDC/CPE-CED/112164/2009) for financial support.

\section{Disclosure statement}

No potential conflict of interest was reported by the author.

\section{Funding}

This work was supported by the Fundação para a Ciência e a Tecnologia (National Foundation for Science and Technology) [PTDC/CPE-CED/112164/2009].

\section{References}

Avalos, B. (2011). Teacher professional development in teaching and teacher education over ten years. Teaching and Teacher Education, 27, 10-20.

Ávalos, B. (2013). Héroes o vilanos? La profesión docente en Chile [Heroes or villains? The teaching profession in Chile]. Santiago de Chile: Editorial Universitaria.

Bahia, S., Freire, I., Amaral, A., \& Estrela, M. T. (2013). The emotional dimension of teaching in a group of Portuguese teachers. Teachers and Teaching Theory and Practice, 19(3), 275-292.

Ball, S. (2003). The teacher's soul and the terrors of performativity. Journal of Education Policy, 18(2), 215-228.

Ballet, K., Kelchtermans, G., \& Loughran, J. (2006). Beyond intensification towards a scholarship of practice: Analysing changes in teachers' work lives. Teachers and Teaching: Theory and Practice, 12(2), 209-229.

Ben-Peretz, M. (2012). Accountability vs. Teacher autonomy. An issue of balance. In C. Day (Ed.), The Routledge international handbook of teacher and school development (pp. 57-66). London: Routledge.

Ben-Peretz, M., \& Flores, M. A. (2018). Tensions and paradoxes in teaching: Implications for teacher education. European Journal of Teacher Education, 41(2), 202-213.

Brante, G. (2009). Multitasking and synchronous work: Complexities in teacher work. Teaching and Teacher Education, 25(3), 430-436.

Brunetti, G. J. (2006). Resilience under fire: Perspectives on the work of experienced, inner city high school teachers in the United States. Teaching and Teacher Education, 22(7), 812-825.

Burke, P., Schuck, S., Aubusson, P., Buchanan, J., Louviere, J. J., \& Prescott, A. (2013). Why do early career teachers choose to remain in the profession? The use of best-worst scaling to quantify key factors. International Journal of Educational Research, 62, 259-268. 
Cribb, A. (2009). Professional ethics: Whose responsibility? In S. Gewirtz, P. Mahony, I. Hextall, \& A. Cribb (Eds.), Changing teacher professionalism. International trends, challenges and ways forward (pp. 31-42). London: Routledge.

Day, C. (1997). Teachers in the twenty-first century: Time to renew the vision. In A. Hargreaves \& R. Evans (Eds.), Beyond educational reform. Bringing teachers back in (pp. 44-61). Buckingham: Open University Press.

Day, C. (1999). Developing teachers. The challenges of lifelong learning. London: Falmer Press.

Day, C. (2017). Teachers' worlds and work. Understanding complexity, building quality. London: Routledge.

Day, C., Flores, M. A., \& Viana, I. (2007). Effects of national policies on teachers' sense of professionalism: Findings from an empirical study in Portugal and in England. European Journal of Teacher Education, 30(3), 249-265.

Day, C., \& Gu, Q. (2009). Veteran teachers: Commitment, resilience and quality retention. Teachers and Teaching Theory and Practice, 15(4), 441-457.

Day, C., \& Sachs, J. (2004). Professionalism, performativity and empowerment: Discourses in the politics, policies and purposes of continuing professional development. In C. Day \& J. Sachs (Eds.), International handbook on the continuing professional development of teachers (pp. 3-32). Maidenhead: Open University Press.

Day, C., \& Smethem, L. (2009). The effects of reform: Have teachers really lost their sense of professionalism? Journal of Educational Change, 10, 141-157.

Direção-Geral de Estatísticas da Educação e Ciência (DGEEC). (2018). Perfil do Docente 2016/ 2017. Lisboa: DGEEC.

Esteve, J. M. (1991). Mudanças Sociais e Função Docente. In A. Nóvoa (Ed.), Profissão Professor (pp. 93-124). Porto: Porto Editora.

Estrela, M. T. (2001). Questões de Profissionalidade e Profissionalismo Docente. In M. Teixeira (Ed.), Ser Professor no Limiar do Século XXI (pp. 113-142). Porto: ISET.

Estrela, M. T. (2014). Velhas e novas profissionalidades, velhos e novos profissionalismos: Tensões, paradoxos, progressos e retrocessos. Investigar Em Educação, 2, 5-30.

Evans, L. (2008). Professionalism, professionality and the development of education professionals. British Journal of Educational Studies, 56(1), 20-38. doi:10.1111/j.14678527.2007.00392.x

Evetts, J. (2009). The management of professionalism: A contemporary paradox. In S. Gewirtz, P. Mahony, I. Hextall, \& A. Cribb (Eds.), Changing teacher professionalism. International trends, challenges and ways forward (pp. 19-30). London: Routledge.

Flores, M. A. (2012). Teachers' work and lives: A European perspective. In C. Day (Ed.), The Routledge international handbook of teacher and school development (pp. 94-107). London: Routledge.

Flores, M. A. (2014). Profissionalismo e Liderança dos Professores. Santo Tirso: De Facto Editores.

Flores, M. A. (2018). Teacher resilience in adverse contexts: Issues of professionalism and professional identity. In M. Wosnitza, F. Peixoto, S. Beltman, \& C. F. Mansfield (Eds.), Resilience in education. Concepts, contexts and connections (pp. 167-184). Cham: Springer.

Flores, M. A., Day, C., \& Viana, I. C. (2007). Profissionalismo Docente em transição. As identidades dos professores em tempos de mudança. Um estudo com professores ingleses e portugueses. In M. A. Flores \& I. C. Viana (Eds.), Profissionalismo docente em transição. As identidades dos professores em tempos de mudança (pp. 7-46). Braga: CIEd.

Flores, M. A., \& Ferreira, F. I. (2016). Education and child poverty in times of austerity in Portugal: Implications for teachers and teacher education. Journal of Education for Teaching, 42(4), 404-416.

Gewirtz, S., Mahony, P., Hextall, I., \& Cribb, A. (2009). Policy, professionalism and practice: Understanding and enhancing teachers' work. In S. Gewirtz, P. Mahony, I. Hextall, \& A. Cribb (Eds.), Changing teacher professionalism. International trends, challenges and ways forward (pp. 3-16). London: Routledge.

Gu, Q., \& Day, C. (2007). Teachers resilience: A necessary condition for effectiveness. Teaching and Teacher Education, 23, 1302-1316. 
Hargreaves, A. (2001). Teaching as a paradoxical profession: Implications for professional development. In P. Xochellis \& Z. Papanaoum (Eds.), Continuing teacher education and school development (symposium proceedings) (pp. 26-38). Thessaloniki: Department of Education, School of Philosophy AUTH.

Hargreaves, A. (2003). Teaching in the knowledge society: Education in the age of insecurity. Maidenhead: Open University Press.

Hargreaves, A., \& Fullan, M. (2012). Professional capital. Transforming teaching in every school. London: Routledge.

Hargreaves, A., \& O'Connor, M. T. (2017). Collaborative professionalism. Wise (World Innovation Summit for Education) report. Qatar: Wise.

Jenkins, K., Smith, H., \& Maxwell, T. (2009). Challenging experiences faced by beginning casual teachers: Here one day and gone the next! Asia-Pacific Journal of Teacher Education, 37(1), 63-78.

Kelchtermans, G. (2009). O comprometimento profissional para além do contrato: Autocomprensão, vulnerabilidade e reflexão dos professores. In M. A. Flores \& A. M. Veiga Simão (Eds.), Aprendizagem e desenvolvimento profissional de professores: Contextos e perspectivas (pp. 61-98). Mangualde: Edições Pedago.

Klette, K. (2002). Reform policy and teacher professionalism in four Nordic countries. Journal of Educational Change, 3(3/4), 265-282.

Lipman, P. (2009). Paradoxes in teaching in neo-liberal times: Education 'reform' in Chicago. In S. Gewirtz, P. Mahony, I. Hextall, \& A. Cribb (Eds.), Changing teacher professionalism. International trends, challenges and ways forward (pp. 67-80). London: Routledge.

Lo, L. N. K. (2012). Issues in teacher professionalism and performativity: Introduction. In C. Day (Ed.), The Routledge international handbook of teacher and school development (pp. 13-18). London: Routledge.

Mansfield, C. F., Beltman, S., Price, A., \& McConney, A. (2012). 'Don't sweat the small stuff: Understanding teacher resilience at the chalkface. Teaching and Teacher Education, 28(3), 357-367.

McCormack, A., \& Gore, J. (2008). If only I could just teach: Early career teachers, their colleagues, and the operation of power. Paper presented at the annual conference of the Australian Association for Research in Education, Brisbane.

Miles, M., \& Huberman, A. M. (1994). Qualitative data analysis (2nd ed.). Thousand Oaks, CA: Sage.

Oolbekkink-Marchand, H. W., Hadar, L. L., Smith, K., Helleve, I., \& Ulvik, M. (2017). Teachers' perceived professional space and their agency. Teaching and Teacher Education, 62, 37-46.

Osborn, M. (2006). Changing the context of teachers' work and professional development: A European perspective. International Journal of Educational Research, 45, 242-253.

Papatraianou, L. H., \& Le Cornu, R. (2014). Problematising the role of personal and professional relationships in early career teacher resilience. Australian Journal of Teacher Education, 39(1), $100-116$.

Pearce, J., \& Morrison, C. (2011). Teacher identity and early career resilience: Exploring the links. Australian Journal of Teacher Education, 36(1), 48-59.

Reeves, J. (2009). Inventing the chareterd teacher. In S. Gewirtz, P. Mahony, I. Hextall, \& A. Cribb (Eds.), Changing teacher professionalism. International trends, challenges and ways forward (pp. 106-116). London: Routledge.

Sachs, J. (2016). Teacher professionalism: Why are we still talking about it? Teachers and Teaching Theory and Practice, 22(4), 413-425.

Sachs, J., \& Mockler, N. (2012). Performance cultures of teaching. Threat or opportunity? In C. Day (Ed.), The Routledge international handbook of teacher and school development (pp. 33-43). London: Routledge.

Sugrue, C. (2004). Rhetorics and realities of CPD across Europe: From cacophony towards coherence. In C. Day \& J. Sachs (Eds.), International handbook on the continuing professional development of teachers (pp. 67-93). Maidenhead: Open University Press. 
Sugrue, C. (2006). A critical appraisal of the impact of international agencies on educational reforms and teachers' lives and work: The case of Ireland? European Educational Research Journal, 5(3-4), 181-195.

Sumsion, J. (2004). Early childhood teachers' constructions of their resilience and thriving: A continuing investigation. International Journal of Early Years Education, 12(3), 275-290.

Willis, J. S., \& Haymore Sandholtz, J. (2009). Constrained professionalism: Dilemmas of teaching in the face of test based accountability. Teachers College Record, 111(4), 1065-1114.

Wosnitza, M., Peixoto, F., Beltman, S., \& Mansfield, C., F. (Eds.). (2018). Resilience in education. Concepts, contexts and connections. Cham: Springer.

Zeng, Y., \& Day, C. (2019). Collaborative teacher professional development in schools in England (UK) and Shanghai (China): Cultures, contexts and tensions. Teachers and Teaching Theory and Practice, 25(3), 379-397. 